\title{
MANAGERIAL SKILL CAMAT UNTUK MENINGKATKAN KINERJA PEGAWAI DI KECAMATAN CIAWI KABUPATEN BOGOR
}

\section{THE MANAGERIAL SKILL OF DISTRICT HEAD TO IMPROVE THE CIVIL SERVANT PERFORMANCE IN CIAWI DISTRICT BOGOR REGENCY}

\author{
Yohanes Mote ${ }^{1 *}$, Rita Rahmawati², G. Goris Seran ${ }^{3}$ \\ 1,3Program Studi Administrasi Publik, Fakultas Ilmu Sosial dan Ilmu Politik, Universitas \\ Djuanda, Jl. Tol Ciawi No. 1, Kotak Pos 35, Bogor 16720 \\ 2Program Studi Magister Administrasi Publik, Sekolah Pascasarjana, Universitas Djuanda, Jl. \\ Tol Ciawi No. 1, Kotak Pos 35, Bogor 16720 \\ *Korespondensi: Yohanes Mote. Email: yohanesmote19@gmail.com
}

(Diterima: 09-05-2019; Ditelaah: 29-06-2019; Disetujui: 15-08-2019)

\begin{abstract}
This study aims to describe the managerial skill of district head to improve the civil servant performance in Ciawi District Bogor Regency. There are four managerial skills necessarily mastered by district head, namely conceptual skill, administrative skill, human relationship skill, and technical skill. The performance of civil servants consists of quality of work, pomptnees, initiative, capability, and communication. The method of this research is associative-quantitative in order to statistically test the relationship of variables by using Rank Spearman Correlation with SPSS version 18. The result of this research indicates coefficient correlation of the managerial skill of district head to the civil servant performance 0.699 , categorized as strong. By t-test, it is gained $\mathrm{t}$-counted 5.948 and $\mathrm{t}$-table $(\mathrm{N}=27)$ 2.886; $\mathrm{t}$-counted $>\mathrm{t}$-table means that Ho is rejected and $\mathrm{Ha}$ is accepted. There is a strong relationship of managerial skill of district head to the civil servant performance. Coefficient determination indicates $48.8 \%$ that means contribution of the managerial skill of district head to the civil servant performance 48.8\%. By counting Weight Mean Score, the managerial skill of district head gains the mean score 4.15 categorized as good. The civil servant performance gains the mean score 4.15 categorized as good.
\end{abstract}

Keywords: Managerial Skill, District Head, Civil Servant Performance.

\begin{abstract}
ABSTRAK
Penelitian ini bertujuan untuk mengetahui managerial skill camat untuk meningkatkan kinerja pegawai di Kecamatan Ciawi Kabupaten Bogor. Terdapat empat kemampuan manajerial yang perlu dikuasai oleh camat, yaitu ketrampilan konseptual, ketrampilan administrasi, ketrampilan hubungan manusiawi, dan ketrampilan teknis. Kinerja pegawai mencakup kualitas kerja, ketetapan waktu, inisiatif, kemampuan, dan komunikasi. Metode penelitian bersifat asosiatif-kuantitatif, yaitu menguji hubungan variabel secara statistik dengan menggunakan Rank Spearman Correlation dari perhitungan SPSS versi 18. Hasil penelitian menunjukkan koefisien korelasi managerial skill camat dengan kinerja pegawai sebesar 0,699, yang dikategorikan kuat. Dengan uji-t, diperoleh t-hitung sebesar 5,948 dan t-tabel ( $N=27)$ sebesar 2,886; $t$-hitung > t-tabel berarti Ho ditolak dan Ha diterima. Ada hubungan yang kuat antara managerial skill camat dengan kinerja pegawai. Koefisien determinasi menunjukkan 48,8\%, artinya kontribusi variabel managerial skill camat terhadap variabel kinerja pegawai sebesar 48,8\%. Dengan menghitung Weight Mean Score, managerial skill camat memiliki skor rata-rata sebesar 4,15 termasuk kategori baik. Kinerja pegawai mempunyai skor rata-rata sebesar 4,15 termasuk kategori baik.
\end{abstract}

Kata Kunci: Managerial Skill, Camat, Kinerja Pegawai.

Yohanes Mote. 2019. Managerial Skill Camat untuk Meningkatkan Kinerja Pegawai di Kecamatan Ciawi Kabupaten Bogor. 


\section{PENDAHULUAN}

Kecamatan atau yang disebut dengan nama lain berdasarkan Peraturan Pemerintah Nomor 17 Tahun 2018 tentang Kecamatan adalah bagian wilayah dari daerah Kabupaten/Kota yang dipimpin oleh camat. Dalam konteks pelaksanaan otonomi daerah, kecamatan adalah satuan kerja perangkat daerah (SKPD) kabupaten/kota yang sebagai wilayah kerja masing-masing daerah tertentu yang dipimpin oleh seorang camat.

Dilihat secara umum, kecamatan merupakan salah satu sistem pemerintahan daerah yang langsung berhadapan dengan masyarakat. Camat yang memimpin bagian wilayah yang dinamakan kecamatan sudah selayaknya memiliki managerial skill untuk mendorong pegawainya berkinerja baik di kecamatan. Demikian halnya di Kecamatan Ciawi Kabupaten Bogor.

Aktivitas pencapaian kinerja pegawai di Kecamatan Ciawi Kabupaten Bogor masih menemui hambatan sebagai berikut: (1) Sumber daya manusia (SDM) yang belum memadai dan rata-rata pegawai berpendidikan SMA sederajat. (2) Perbedaan pendidikan yang dimiliki oleh pemimpin dan pegawai, sehingga terdapat pegawai yang tidak mampu menggunakan komputer dalam mengoperasikan tupoksi kinerja masing-masing pegawai.

Di samping itu, masih terdapat hambatan-hambatan lain yang dapat mempengaruhi penyelesaian tugas, fungsi dan pekerjaan serta peningkatan kinerja pegawai. Hal ini dapat dilihat dari hal-hal sebagai berikut:

1. Adanya pegawai yang masih terlambat masuk ke kantor di pagi hari dan tidak mengikuti apel pagi dengan jumlah satu sampai empat orang pegawai.

2. Masih ada pegawai yang masuk ke kantor jam yang sudah ditentukan oleh organisasi sekitar satu dua orang pegawai, sedangkan pegawai yang lain masuk sesuai jam yang sudah ditentukan oleh organisasi.
3. Sekitar satu sampai tiga orang pegawai yang kadang-kadang kinerja pegawai tidak selesai tepat pada waktu, sedangkan pegawai yang lain kerjanya tepat pada waktunya sesuai peraturan yang ditetapkan oleh oganisasi di Kecamatan Ciawi Kabupaten Bogor.

4. Tidak selesai pekerjaan dengan baik yang terjadi pada pegawai sekitar satu dua orang pegawai yang kadangkadang dalam setengah jam pegawai pemborosan kerja, sedangkan pegawai yang lain dalam partisipasi dalam tugas pekerjaan di Kantor Kecamatan Ciawi.

Hambatan-hambatan tersebut mempengaruhi peningkatan kinerja pegawai di Kecamatan Ciawi Kabupaten Bogor. Oleh karena itu diperlukan kemampuan managerial camat untuk diterapkan di Kecamatan Ciawi Kabupaten Bogor. Penerapan kemampuan managerial camat ini dapat dilihat dari kemampuan mengembangkan hubungan yang harmonis dengan semua pegawai guna meningkatkan prestasi dan kemampuan pegawai sesuai dengan tugasnya.

Berdasarkan uraian latar belakang di atas, peneliti tertarik meneliti managerial skill camat untuk meningkatkan kinerja pegawai di Kecamatan Ciawi Kabupaten Bogor.

\section{MATERI DAN METODE}

\section{Teori/Konsep yang Relevan}

Terdapat dua konsep dalam penelitian ini, yaitu managerial skill dan kinerja pegawai.

Managerial skill adalah kemampuan yang dimiliki untuk berusaha dan bekerja dalam suatu organisasi. Managerial berhubungan dengan kemampuan orang yang berketrampilan yang tinggi dalam mengambil keputusan berwenang dan bertanggung jawab untuk membuat mengatur dalam pekerjaan, mengatur memimpin, mengkoordinasi, mengawasi dan mengendalikan pelaksanaannya untuk mencapai sasaran dan tujuan organisasi tersebut. 
Ketrampilan managerial menurut pendapat Wahyudi (2012: 69) mencakup empat bidang yang perlu dikuasai, yaitu: (1) ketrampilan konseptual (conceptual skill), (2) ketrampilan administrasi (admistrative skill), (3) ketrampilan manusiawi (human relationship skill), dan (4) ketrampilan teknis (technical skill). Keempat jenis ketrampilan tersebut diuraikan sebagai berikut:

1) Ketrampilan konseptual (conceptual skill) adalah ketrampilan yang harus dimiliki oleh seorang manager untuk menentukan strategi, merencanakan, merumuskan kebijakan, serta memutuskan sesuatu yang terjadi dalam organisasi kecamatan sebagai lembaga pemerintahan. Untuk maksud tersebut, manajer pemerintahan sangat memerlukan konsep-konsep yang didasarkan pada pemahaman tentang organisasi, cara mengatasi masalah, dan mempertahankan, serta meningkatkan perkembangan organisasi. Manajer pada umumnya memiliki kemampuan yang cukup memadai dalam membuat perencanaan organisasi pemerintah secara komprehenshif, terpadu dan efisien.

2) Ketrampilan administrasi (administrative skill) adalah keseluruhan proses ketrampilan bekerja sama dengan memanfaatkan dan memberdayakan segala sumber yang tersedia melalui aktivitas perencanaan, pengorganisasian, pengendalian, penggerakan, pemotivasian, penyusunan kepegawaian, pengawasan dan supervisi.

3) Ketrampilan hubungan manusiawi (human relationship skill) adalah kemampuan mengembangkan hubungan yang harmonis dengan semua anggota lembaga atau organisasi. Ketrampilan ini ditunjukkan dalam cara seorang manajer berhubungan dengan orang lain, termasuk kemampuan untuk memotivasi, memberikan sarana, koordinasi, bimbingan, komunikasi, dan memecahkan konflik.
4) Ketrampilan teknis (technical skill) adalah kemampuan untuk menggunakan pengetahuan, metode-metode, prosedur, tehnik dan akal yang diperlukan untuk melaksanakan tugas spesifik yang diperoleh lewat pengalaman, pendidikan, dan pelatihan.

Berkaitan dengan kinerja pegawai, kinerja tanpa sumber daya manusia tidak akan dicapai hasil kerja yang diharapkan suatu organisasi. Untuk memudahkan pengkajian kinerja pegawai, Mitchel (Sedarmayanti, 2001: 51) mengemukakan lima indikator kinerja pegawai, yaitu: (1) kualitas kerja (quality of work), (2) ketetapan waktu (pomptnees), (3) inisiatif (initiative), (4) kemampuan (capability), dan (5) komunikasi (communication). Kelima indikator kinerja pegawai tersebut diuraikan sebagai berikut:

1) Kualitas kerja (quality of work) adalah kualitas kerja yang dicapai berdasarkan syarat-syarat kesesuaian dan kesiapan yang tinggi sehingga pada gilirannya dapat melahirkan penghargaan dan kemajuan serta perkembangan organisasi melalui peningkatan pengetahuan dan ketrampilan secara sistematis sesuai dengan tuntutan ilmu pengetahuan dan teknologi yang semakin berkembang pesat.

2) Ketetapan waktu (pomptnees) berkaitan dengan sesuai atau tidaknya waktu penyelesaian pekerjaan dengan target waktu yang direncanakan. Setiap pekerjaan diusahakan untuk selesai sesuai dengan rencana agar tidak mengganggu pekerjaan yang lain.

3) Inisiatif (initiative) berkaitan dengan adanya kesadaran diri untuk melakukan sesuatu dalam melaksanakan tugas-tugas dan tanggung jawab. Bawahan atau pegawai dapat melaksanakan tugas tanpa harus bergantung terus menerus kepada atasan.

4) Kemampuan (capability) yaitu di antara beberapa faktor yang mempengaruhi kinerja seseorang, ternyata yang dapat diintervensi atau diterapi melalui 
pendidikan dan latihan adalah faktor kemampuan yang dapat dikembangkan.

5) Komunikasi (communication) merupakan interaksi yang dilakukan oleh atasan kepada bawahan untuk mengemukakan saran dan pendapat dalam memecahkan masalah yang dihadapi. Komunikasi dapat menimbulkan kerja sama yang lebih baik dan dapat menciptakan hubungan-hubungan yang harmonis di antara pegawai dan atasan, yang juga dapat menimbulkan perasaan senasib sepenanggungan.

\section{Metode}

Penelitian ini menggunakan metode penelitian asosiatif-kuantitatif, yaitu menguji hubungan variabel secara statistik.

Dalam penelitian ini, populasi adalah wilayah generalisasi yang terdiri atas subyek atau objek mempunyai kualitas dan karakteristik tertentu yang telah ditetapkan oleh peneliti dan kemudian untuk mempelajari dan kemudian ditarik kesimpulan (Sugiyono, 2012: 80). Sehingga yang menjadi populasi adalah seluruh pegawai di Kecamatan Ciawi Kabupaten Bogor sebanyak 27 orang. Sampel penelitian ditarik secara sensus, yaitu cara mengumpulkan data dengan jalan mencatat atau meneliti seluruh elemen yang menjadi obyek penelitian. Semua pegawai di Kecamatan Ciawi Kabupaten Bogor yang berjumlah 27 orang dijadikan sebagai sampel penelitian.

Teknik pengumpulan data yang digunakan adalah:

1) Studi kepustakaan (library research), yaitu teknik pengumpulan data yang sifatnya sekunder yang berhubungan dengan bidang yang diteliti, baik berupa buku, dokumen, maupun peraturanperaturan.

2) Studi lapangan (field research), yaitu teknik pengumpulan data yang sifatnya primer dengan turun langsung ke objek yang akan diteliti, yaitu di Kecamatan Ciawi Kabupaten Bogor. Adapun teknik pengumpulan data primer terdiri dari: a) Wawancara, yaitu sejumlah daftar pertanyaan yang disusun dalam bentuk tulisan untuk mendapatkan informasi secara langsung dengan mengungkapkan pertanyaan-pertanyaan kepada responden.

b) Observasi, yaitu pengamatan langsung di lokasi penelitian. Observasi digunakan untuk melengkapi data baik yang diperoleh dari wawancara dan pencatatan serta untuk mengetahui keadaan yang sebenarnya di lokasi penelitian.

c) Angket, yaitu sejumlah pertanyaan yang disusun dalam bentuk tulisan untuk mendapatkan data yang diperlukan dari jawaban respoden secara tertulis. Adapun jenis angket yang digunakan adalah angket tertutup yang sudah disediakan jawabannya sehingga responden tinggal memilih. Alternatif jawaban disediakan dengan pilihan dalam bentuk gradasi lima, yaitu: (a) Pilihan jawaban A sangat baik, (b) Pilihan jawaban B baik, (c) Pilihan jawaban $C$ cukup baik, (d) Pilihan jawaban D tidak baik, dan (e) Pilihan jawaban E dengan sangat tidak baik.

Pengolahan dan analisis data untuk variabel penelitian secara mandiri menggunakan Weight Mean Score (WMS) untuk menghitung nilai/angka/skor rata-rata terhadap pilihan jawaban responden. Setiap jawaban responden diberi skor berdasarkan lima gradasi, yaitu: (a) Alternatif jawaban A diberi skor 5. (b) Alternatif jawaban B diberi skor 4. (c) Alternatif jawaban C diberi skor 3. (d) Alternatif jawaban D diberi skor 2. (e) Alternatif jawaban E diberi skor 1. Adapun rumus WMS adalah sebagai berikut:

$$
\mathrm{M}=\frac{\Sigma f(x)}{n}
$$

Keterangan:

M: Perolehan angka kriteria penafsiran.

$\mathrm{f}$ : frekuensi jawaban responden.

$\mathrm{x}$ : Pembobotan. 
n: Jumlah responden.

$\Sigma$ : Penjumlahan.

Hasil perhitungan WMS tersebut diinterpretasi berdasarkan kriteria penilaian dan angka penafsiran sebagaimana ditunjukkan pada Tabel 1.

Tabel 1. Kriteria Penilaian Berdasarkan Angka Penafsiran

\begin{tabular}{ll}
\hline Angka Penafsiran & Kriteria Penilaian \\
\hline $4,24-5,00$ & Sangat Baik \\
\hline $3,43-4,23$ & Baik \\
\hline 2,62-3,42 & Cukup Baik \\
\hline $1,81-2,61$ & Kurang Baik \\
\hline Sumber: Sugiyono (2012: 74$)$ & Tidak Baik \\
\hline
\end{tabular}

Kemudian, pengolahan dan analisis data untuk hubungan/korelasi variabel penelitian dilakukan secara statistik. Untuk menguji hubungan managerial skill camat dengan kinerja pegawai, maka dilakukan uji statistik Rank Spearman Correlation yang menggunakan SPSS versi 18. Interval koefisien korelasi dan penafsiran tingkat hubungan ditunjukkan pada Tabel 2.

Tabel 2. Interval Koefisien dan Tingkat Hubungan

\begin{tabular}{ll}
\hline Interval Koefisien & Tingkat Hubungan \\
\hline $0,00-0,19$ & Sangat rendah \\
\hline $0,20-0,39$ & Rendah \\
\hline $0,40-0,59$ & Sedang \\
\hline $0,60-0,79$ & Kuat \\
\hline $0,80-1,00$ & Sangat kuat \\
\hline
\end{tabular}

Uji korelasi dilanjutkan dengan uji hipotesis untuk mengetahui diterima atau ditolaknya hipotesis (Ho atau Ha). Adapun pengujian signifikan koefisien korelasi dilakukan dengan menggunakan rumus ttest.

Hipotesis penelitian dirumuskan sebagai berikut:

1) Ho: Tidak ada hubungan yang kuat antara managerial skill camat dengan kinerja pegawai.

2) Ha: Ada hubungan yang kuat antara managerial skill camat dengan kinerja pegawai.
Untuk mengetahui kontribusi variabel managerial skill camat (variabel X) terhadap peningkatan kinerja pegawai (variabel Y), digunakan perhitungan koefisien determinasi (Kd).

\section{HASIL DAN PEMBAHASAN}

Variabel managerial skill camat diukur berdasarkan empat dimensi, yaitu ketrampilan konseptual (conceptual skill), ketrampilan administrasi (admistrative skill), ketrampilan manusiawi (human relationship skill), dan ketrampilan teknis (technical skill). Hasil rekapitulasi pengolahan data variabel managerial skill camat di Kecamatan Ciawi Kabupaten Bogor ditunjukkan pada Tabel 3.

Tabel 3. Rekapitulasi Tanggapan Responden terhadap Managerial Skill Camat

\begin{tabular}{|c|c|c|c|}
\hline No. & Indikator & $\begin{array}{l}\text { Rata-rata } \\
\text { Skor }\end{array}$ & Kriteria \\
\hline 1. & Merencanakan & 4,25 & $\begin{array}{l}\text { Sangat } \\
\text { Baik }\end{array}$ \\
\hline 2. & $\begin{array}{l}\text { Merumuskan } \\
\text { kebijakan }\end{array}$ & 4,25 & $\begin{array}{l}\text { Sangat } \\
\text { Baik }\end{array}$ \\
\hline 3. & $\begin{array}{l}\text { Cara mengatasi } \\
\text { masalah }\end{array}$ & 4,29 & $\begin{array}{l}\text { Sangat } \\
\text { Baik }\end{array}$ \\
\hline 4. & Pengorganisasian & 4,29 & $\begin{array}{l}\text { Sangat } \\
\text { Baik }\end{array}$ \\
\hline 5. & Pengendalian & 4,07 & Baik \\
\hline 6. & Penggerakkan & 4,22 & Baik \\
\hline 7. & Motivasi & 3,96 & Baik \\
\hline 8. & Penyusunan pegawai & 4,03 & Baik \\
\hline 9. & Pengawasan & 4,14 & Baik \\
\hline 10. & Pemberian sarana & 4,40 & $\begin{array}{l}\text { Sangat } \\
\text { Baik }\end{array}$ \\
\hline 11. & Koordinasi & 3,85 & $\begin{array}{l}\text { Cukup } \\
\text { Baik }\end{array}$ \\
\hline 12. & Bimbingan & 4,18 & Baik \\
\hline 13. & Komunikasi & 4,00 & Baik \\
\hline 14. & Pendidikan latihan & 4,11 & Baik \\
\hline \multicolumn{2}{|c|}{ Rata-rata Skor } & 4,15 & Baik \\
\hline
\end{tabular}

Sumber: Data Penelitian yang Diolah, 2019

Pada Tabel 3, nilai keseluruhan dimensi yang diukur menunjukkan managerial skill camat di Kantor Kecamatan Ciawi Kabupaten Bogor berjalan dengan baik. Dalam hal ini dapat dilihat dari angka penafsiran sebesar 4,15, termasuk dalam kriteria baik. Kondisi baik ini dapat dilihat 
dari adanya strategi merencanakan, merumuskan kebijakan, cara mengatasi masalah, pengorganisasian, pengendalian, penggerakan, motivasi, penyusunan pegawai, pengawasan, pemberian sarana, koordinasi, bimbingan, komunikasi, pendidikan dan pelatihan. Semuanya dijalankan oleh camat dengan menggunakan kemampuan yang dimiliki kepada pegawai di Kecamatan Ciawi Kabupaten Bogor.

Variabel kinerja pegawai diukur berdasarkan lima dimensi, yaitu kualitas kerja (quality of work), ketetapan waktu (pomptnees), inisiatif (initiative), kemampuan (capability), dan komunikasi (communication). Hasil rekapitulasi pengolahan data variabel kinerja pegawai di Kecamatan Ciawi Kabupaten Bogor ditunjukkan pada Tabel 4.

Tabel 4. Rekapitulasi Tanggapan Responden terhadap Kinerja Pegawai

\begin{tabular}{llll}
\hline No. & Indikator & $\begin{array}{l}\text { Rata-Rata } \\
\text { Skor }\end{array}$ & Kriteria \\
\hline 1. & Penghargaan & 4,40 & $\begin{array}{l}\text { Sangat } \\
\text { Baik }\end{array}$ \\
\hline 2. & Kemajuan & 4,40 & $\begin{array}{l}\text { Sangat } \\
\text { Baik }\end{array}$ \\
\hline 3. & $\begin{array}{l}\text { Peningkatan } \\
\text { pengetahuan }\end{array}$ & 3,96 & Baik \\
\hline 4. & $\begin{array}{l}\text { Waktu penyelesaian } \\
\text { pekerjaan }\end{array}$ & 4,48 & $\begin{array}{l}\text { Sangat } \\
\text { Baik }\end{array}$ \\
\hline 5. & $\begin{array}{l}\text { Kesadaran diri } \\
\text { Baik }\end{array}$ & $\begin{array}{l}\text { Sangat } \\
\text { Baik }\end{array}$ \\
\hline 6. & $\begin{array}{l}\text { Faktor yang mempe- } \\
\text { pegawai }\end{array}$ & 4,11 & Baik \\
\hline 7. & $\begin{array}{l}\text { Komunikasi atasan } \\
\text { kepada bawahan }\end{array}$ & 2,83 & $\begin{array}{l}\text { Cukup } \\
\text { Baik }\end{array}$ \\
\hline 8. & Komunikasi yang baik & 4,59 & $\begin{array}{l}\text { Sangat } \\
\text { Baik }\end{array}$ \\
\hline Rata-rata Skor & 4,15 & Baik \\
\hline
\end{tabular}

Sumber: Data Penelitian yang Diolah, 2019

Pada Tabel 4, nilai keseluruhan dimensi yang diukur menunjukkan kinerja pegawai di Kantor Kecamatan Ciawi Kabuapten Bogor berjalan dengan baik. Dalam hal ini dapat dilihat dari angka penafsiran sebesar 4,15, termasuk dalam kriteria baik. Kondisi baik tersebut dapat dilihat dari adanya penghargaan, kemajuan, peningkatan pengetahuan, waktu penyelesaian pekerjaan, kesadaran diri, faktor yang mempengaruhi kinerja pegawai, komunikasi atasan kepada bawahan/pegawai, dan komunikasi yang baik. Semuanya dilakukan oleh pegawai dalam rangka mendukung kemajuan pelaksanaan tugas dan fungsi organisasi di Kecamatan Ciawi Kabupaten Bogor.

Pengujian korelasi managerial skill camat dengan kinerja pegawai menggunakan uji statistik Rank Spearman Correlation dengan SPSS versi 18. Adapun hasil uji statistik korelasi Rank Spearman dapat dilihat pada Tabel 5 .

Tabel 5. Hasil Uji Stasistik Korelasi Rank Spearman

\begin{tabular}{|c|c|c|c|}
\hline \multicolumn{4}{|c|}{ Correlations } \\
\hline & & Managerial & Kinerja \\
\hline \multirow[t]{4}{*}{ Managerial } & Correlation & 1.000 & .699 \\
\hline & Coefficient & & \\
\hline & Sig. (2 tailed) & . & .000 \\
\hline & $\mathrm{N}$ & 27 & 27 \\
\hline \multirow[t]{3}{*}{ Kinerja } & $\begin{array}{l}\text { Correlation } \\
\text { Coefficient }\end{array}$ & .699 & 1.000 \\
\hline & Sig. (2-tailed) & .000 & \\
\hline & $\mathrm{N}$ & 27 & 27 \\
\hline
\end{tabular}

**. Correlation is significant at the 0.01 level (2-tailed).

Sumber: Data Penelitian yang Diolah, 2019

Hasil uji statistik Rank Spearman Correlation menunjukkan koefisien korelasi managerial skill camat dengan kinerja pegawai sebesar 0,699. Artinya, terdapat hubungan yang kuat antara managerial skill camat dengan kinerja pegawai.

Uji hipotesis merupakan alat pengukur untuk mengetahui diterima atau ditolaknya hipotesis. Adapun pengujian signifikan koefisien korelasi dilakukan dengan menggunakan rumus t-test sebagai berikut:

$$
\begin{aligned}
& t=r \sqrt{\frac{N-2}{1-r^{2}}} \\
& t=0.699 \sqrt{\frac{27-2}{1-0,488}}
\end{aligned}
$$




$$
\begin{aligned}
& t=0,699 \sqrt{48,82} \\
& t=5,948
\end{aligned}
$$

Hasil perhitungan t-test menunjukkan nilai $t_{\text {-hitung }}$ sebesar 5,948 dan $t_{\text {-tabel }} \mathrm{N}=27$ sebesar 2,886. Dengan demikian, $t_{\text {-hitung }}>t$. tabel berarti Ho ditolak dan Ha diterima. Artinya, terdapat hubungan yang signifikan antara managerial skill camat dengan kinerja pegawai.

Untuk mengetahui sejauhmana variabel managerial skill camat berkontribusi mempengaruhi peningkatan kinerja pegawai, digunakan perhitungan koefisien determinasi (Kd), yaitu:

$$
\begin{aligned}
& \mathrm{Kd}=\mathrm{p}^{2} \times 100 \% \\
& \mathrm{Kd}=0,6992 \times 100 \% \\
& \mathrm{Kd}=0,488 \times 100 \% \\
& \mathrm{Kd}=48,8 \% .
\end{aligned}
$$

Dengan demikian dapat ditafsirkan besarnya kontribusi managerial skill camat (variable $\mathrm{X}$ ) terhadap kinerja pegawai (variabel Y) sebesar 48,8\%, dan kontribusi faktor lain adalah sebesar $51,2 \%$.

\section{KESIMPULAN DAN IMPLIKASI}

\section{Kesimpulan}

Pembahasan tentang managerial skill camat untuk meningkatkan kinerja pegawai di Kecamatan Ciawi Kabupaten Bogor dapat disimpulkan sebagai berikut:

1) Pembahasan tentang managerial skill camat di Kecamatan Ciawi Kabupaten Bogor menunjukkan skor rata-rata 4,15, termasuk kategori baik. Kondisi baik ini tercipta karena adanya strategi untuk merencanakan, memutuskan kebijakan, cara mengatasi masalah, cara struktur pengorganisasian, pengendalian, penggerakan, motivasi, penyusunan pegawai, pengawasan, pemberian sarana, koordinasi, bimbingan, komunikasi, pendidikan dan latihan, yang semuanya ini dilakukan melalui managerial skill camat dalam mendukung dan meningkatkan kinerja pegawai dan program-program yang ditetapkan pada organisasi dalam hal ini di Kecamatan Ciawi Kabupaten Bogor.

2) Pembahasan tentang kinerja pegawai di Kecamatan Ciawi Kabupaten Bogor menunjukkan skor rata-rata 4,15, termasuk kategori baik. Kondisi baik ini tercipta karena adanya penghargaan yang diberikan oleh atasan, kemajuan kualitas pekerjaan pegawai, peningkatan pengetahuan dalam aktivitas pengelola pekerjaan, penyelesaian pekerjaan kemajuan sesuai dengan target yang telah ditetapkan, inisiatif setiap pegawai dalam melakukan pekerjaan tidak tergantung pada atasan. Faktor yang mempengaruhi kinerja pegawai bisa diatasi melalui pendidikan dan belajar, pegawai menyampaikan pendapat kepada atasan, keluhan yang pegawai alami dalam proses pekerjaan saat evaluasi diadakan oleh pimpinan, komunikasi antar pegawai selalu ada antara rekan satu dan yang lain di dalam organisasi dalam hal ini di Kecamatan Ciawi Kabupaten Bogor.

3) Hasil olah statistik dengan menggunakan korelasi Rank Spearman berdasarkan SPSS versi 18 menunjukkan koefisien korelasi managerial skill camat dengan kinerja pegawai sebesar 0,699, yang dikategorikan kuat. Dengan t-test, diperoleh nilai t-hitung sebesar 5,948 dan t-tabel $n=27$ sebesar 2,886, $t$ hitung > t-tabel berarti Ho ditolak dan Ha diterima, artinya ada hubungan signifikan managerial skill camat dengan kinerja pegawai. Koefisien determinasi (Kd) menunjukkan angka sebesar 48,8\%, artinya bahwa kontribusi variabel managerial skill camat terhadap kinerja pegawai sebesar $48,8 \%$, sedangkan $51,2 \%$ bersumber dari faktor lain.

\section{Implikasi}

Terdapat empat jenis managerial skill camat yang diterapkan terhadap pegawai di Kecamatan Ciawi Kabupaten Bogor, yaitu: 
1) Ketrampilan konseptual merupakan ketrampilan yang harus dimiliki oleh Managerial untuk menentukan strategi.

2) Ketrampilan administrasi merupakan keseluruhan proses ketrampilan bekerja sama dengan memanfatkan dan memberdaya segala sumber daya yang tersedia melalui aktivitas perencanaan.

3) Ketrampilan hubungan manusiawi adalah kemampuan mengembangkan hubungan yang harmonis dengan semua anggota dalam organisasi.

4) Ketrampilan teknis adalah kemampuan untuk menggunakan pengetahuan.

Hal demikian secara praktis berimplikasi terhadap upaya-upaya yang dilakukan camat melalui managerial skill-nya. Semakin camat memberikan motivasi dan saran bahkan keluhan pegawai terhadap atasan maupun dalam merasakan melakukan pekerjaan mereka, apapun yang disampaikan melalui managerial skill camat terhadap seluruh pegawai bisa berjalan dengan baik. Dalam kinerja pegawai pun, kerja sama rekan satu dan yang lainnya dalam melakukan aktivitas kerja di Kecamatan Ciawi memberikan harapan untuk mendukung program-program yang ada dalam organisasi dan akan tercapai dalam tujuan yang telah ditetapkan.

\section{DAFTAR PUSTAKA}

\section{Buku:}

Ali, Lukman, dkk. 1997. Kamus Besar Bahasa Indonesia. Cetakan II, Jakarta: Balai Pustaka.

Arni, Muhammad. 2001. Komunikasi Organisasi. Jakarta: Bumi Aksara.

Handoko, T. Hani. 1995. Manajemen. Yogyakarta: BPFE.

Mulyasa, E. 2002. Manajemen Berbasis Sekolah. Cetakan I, Bandung: PT. Remaja Rasindo.

Siagian, S. P. 2002. Kiat Meningkatkan Produktivitas Kerja. Jakarta: Rineka Cipta.
Soehardi. 2003. Esensi Perilaku Organisasional. Yogyakarta: Penerbit Fakultas Ekonomi Sarjanawiyata Tamansiswa.

Sugiyono. 2012. Metode Penelitian Kuantitatif, Kualitatif dan $R \& D$. Bandung: Alfabeta.

Jurnal:

Haryadi, Wanda Maulana; Pratidina, Ginung dan Seran, G. Goris. 2016. "Studi Manajemen Pembinaan Olahraga Sepakbola di Klub Persatuan Sepakbola Kota Bogor oleh Kantor Pemuda dan Olahraga Kota Bogor". Jurnal GOVERNANSI, Volume 2 Nomor 1, April, 41-46.

\section{Peraturan Perundang-undangan:}

Peraturan Pemerintah Republik Indonesia Nomor 17 Tahun 2018 tentang Kecamatan. 